\title{
Measure Guideline: Replacing Single-Speed Pool Pumps with Variable Speed Pumps for Energy Savings
}

A. Hunt and S. Easley

Building America Retrofit Alliance (BARA)

May 2012 


\section{NOTICE}

This report was prepared as an account of work sponsored by an agency of the United States government. Neither the United States government nor any agency thereof, nor any of their employees, subcontractors, or affiliated partners makes any warranty, express or implied, or assumes any legal liability or responsibility for the accuracy, completeness, or usefulness of any information, apparatus, product, or process disclosed, or represents that its use would not infringe privately owned rights. Reference herein to any specific commercial product, process, or service by trade name, trademark, manufacturer, or otherwise does not necessarily constitute or imply its endorsement, recommendation, or favoring by the United States government or any agency thereof. The views and opinions of authors expressed herein do not necessarily state or reflect those of the United States government or any agency thereof.

Available electronically at http://www.osti.gov/bridge

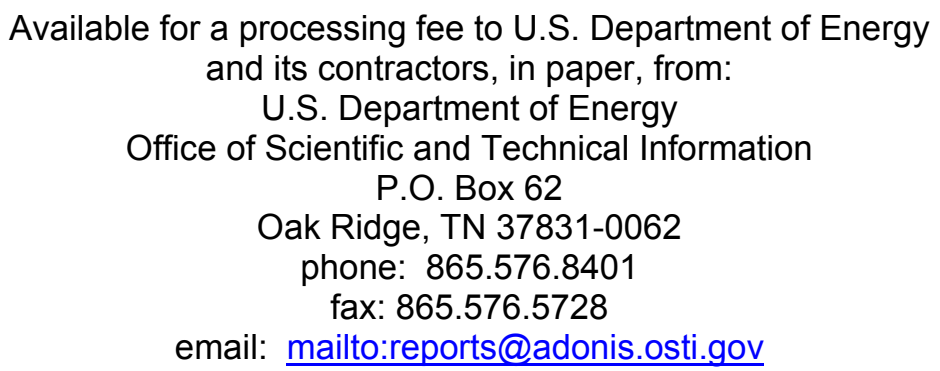

Available for sale to the public, in paper, from:

U.S. Department of Commerce

National Technical Information Service

5285 Port Royal Road

Springfield, VA 22161

phone: 800.553 .6847

fax: 703.605 .6900

email: orders@ntis.fedworld.gov

online ordering: http://www.ntis.gov/ordering.htm 


\title{
Measure Guideline: Replacing Single-Speed Pool Pumps with Variable Speed Pumps for Energy Savings
}

\author{
Prepared for: \\ Building America \\ Building Technologies Program \\ Office of Energy Efficiency and Renewable Energy \\ U.S. Department of Energy
}

Prepared by:

A. Hunt and S. Easley

Building Media and the Building America Retrofit Alliance (BARA)

4301 Lancaster Pike, Bldg. 721

Wilmington, De 19805

NREL Technical Monitor: Cheryn Engebrecht

Prepared under Subcontract No. KNDJ-0-40336-00

May 2012 
[This page left blank] 


\section{Contents}

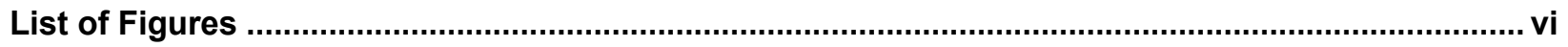

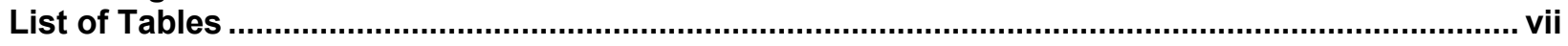

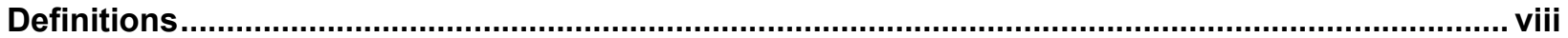

Forward

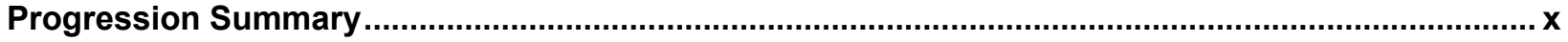

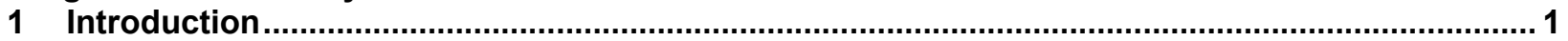

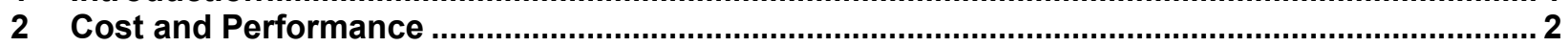

2.1 Typical Energy Usage of Single-Speed Pool Pumps ....................................................2

2.2 Energy Savings of Variable Speed Pool Pumps ........................................................ 3

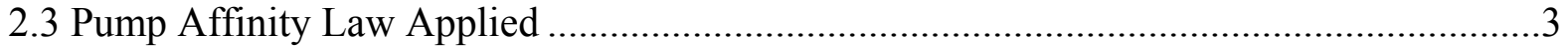

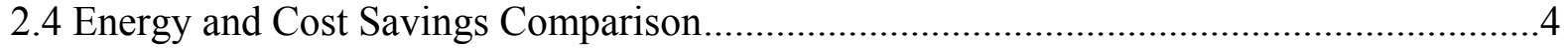

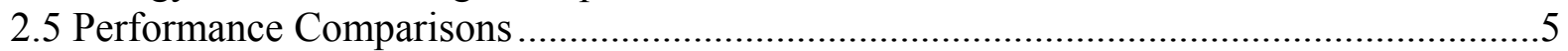

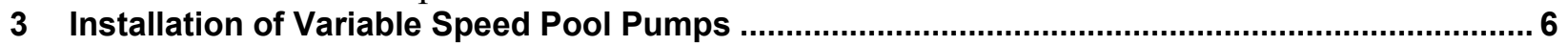

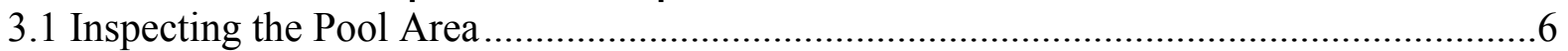

3.2 Measuring the Pool and Calculating Pool Volume........................................................6

3.3 Evaluating Energy Usage of Existing Pool Pump ....................................................

3.4 Estimate Energy Usage and Savings of a New Pool Pump .............................................

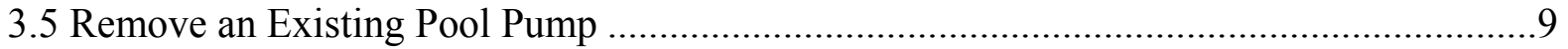

3.6 Installing a Variable Speed Pump ....................................................................... 11

3.7 Connecting Fittings and Making Electrical Connections ........................................... 11

3.8 Calibrating Variable Speed Pump for Optimum Performance .....................................11

3.9 Verification and Filtration Flow Rate Testing ........................................................... 12

3.10 Programmable Pumps and Maintenance..................................................... 13

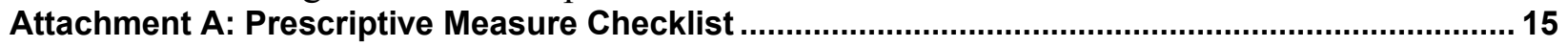

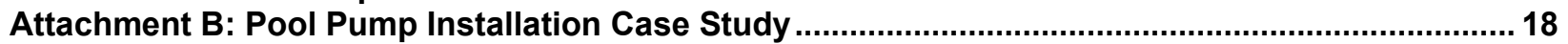

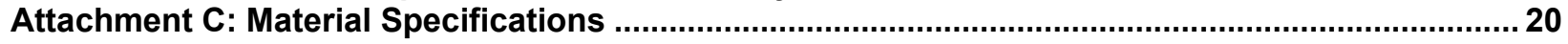

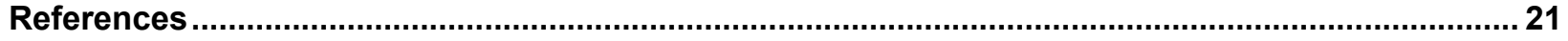




\section{List of Figures}

Figure 1. A variable speed pool pump can obtain similar gpm rates as a single-speed pump but at greater energy efficiencies.

Figure 2. Inspecting the equipment pad for potential health and safety risks is critical before beginning work.

Figure 3. How to determine total volume in gallons................................................................. 7

Figure 4. The RMS kilowatt meter can quickly and easily determine the pool pump's electrical consumption rate.

Figure 5. Extreme caution should be used when using the RMS kilowatt meter to determine pool pump electrical usage.

Figure 6. A reciprocating saw often works well to cut PVC pipe during the installation process..... 9

Figure 7. Thread sealant or pipe glue will help ensure fittings remain connected and leak-free..... 10

Figure 8. Make sure the ground bonding wire is securely fastened to the pump's bonding lug..... 11

Figure 9. The skimmer is the port that draws water from the pool and into the filtration system... 11

Unless otherwise noted, all figures were created by the BARA team. 


\section{List of Tables}

Table 1. Pool Pump Replacement vs. Upgrading to an ENERGY STAR Home ................................ 2

Table 2. The Pump Affinity Law - Applied ......................................................................................... 4

Table 3. Single-Speed Pool Pump Replacement with Variable Speed Pump Operating Cost

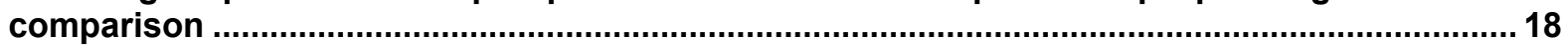

Table 4. Waterfall Pump Operating Cost Comparison. ........................................................................ 19

Unless otherwise noted, all tables were created by the BARA team. 


\section{Definitions}

$\begin{array}{ll}\text { APSP } & \text { The Association of Pool and Spa Professionals } \\ \text { DSIRE } & \text { The Database of State Incentives for Renewables \& Efficiency } \\ \text { GPM } & \text { Gallons per minute } \\ \text { KW } & \text { Kilowatt } \\ \text { KWH } & \text { Kilowatt hour } \\ \text { LED } & \text { Light Emitting Diode } \\ \text { NRDC } & \text { Natural Resources Defense Council } \\ \text { PMM } & \text { Permanent Magnet Motor } \\ \text { RMS } & \text { Root Mean Square } \\ \text { RPM } & \text { Revolutions per minute } \\ \text { TDH } & \text { Total Dynamic Head }\end{array}$




\section{Forward}

One of the most significant consumers of energy in homes with swimming pools are pool pumps, which keep pools clean by circulating water through filters. Pool pumps can consume 3,000 to over 5,000 $\mathrm{kWh}$ per year. In addition, pumps may also circulate water through heaters, cleaners (also known as sweeps), water features, or fountains. Typically these pumps may have 1- or 2-horsepower (hp) motors that run at least five to six hours per day, if not around the clock, consuming energy.

The authors hope that this document is useful to a wide audience: builders, remodelers, home performance contractors, and homeowners. However, some of the procedures presented here require specialized equipment or expertise. In addition, some alterations to existing pool filtration, heating, and circulation systems may require a specialized license; those implementing pool pump exchanges or replacements should not go beyond their expertise or qualifications.

This document begins with a discussion on the overall function and purpose of pool pumps. It continues with an analysis of energy consumption and efficiency ratings of traditional pool pumps and highlights how pool pumps can contribute to increasingly high energy costs for the homeowner. The document will evaluate potential energy savings by replacing traditional single-speed pool pumps with variable speed pool pumps, and provide a basic cost comparison between continued uses of traditional pumps versus new pumps. A simple step-by-step process for inspecting the pool area and installing a new pool pump will follow.

The overall procedure for assessing and replacing existing pool pumps is as follows:

1. Inspect the pool area and identify possible hazards, then ensure the area is ready for maintenance and pool pump replacement.

2. Calculate the volume of the swimming pool to determine the total amount of flow required to adequately circulate water through the filtration system.

3. Determine the wattage use of the existing pool pump and amount of usage on a daily basis to estimate total annual energy use of the pump.

4. Estimate expected usage of new pump to calculate expected energy use and savings.

5. Remove existing pool pump.

6. Install new variable speed pool pump.

7. Calibrate flow of new pool pump to obtain adequate circulation at lowest possible motor speed.

\section{Acknowledgements}

Special thanks to Jeff Farlow of Pentair Water Pool and Spa for providing subject matter expertise, content, data, and graphics. 


\section{Progression Summary}

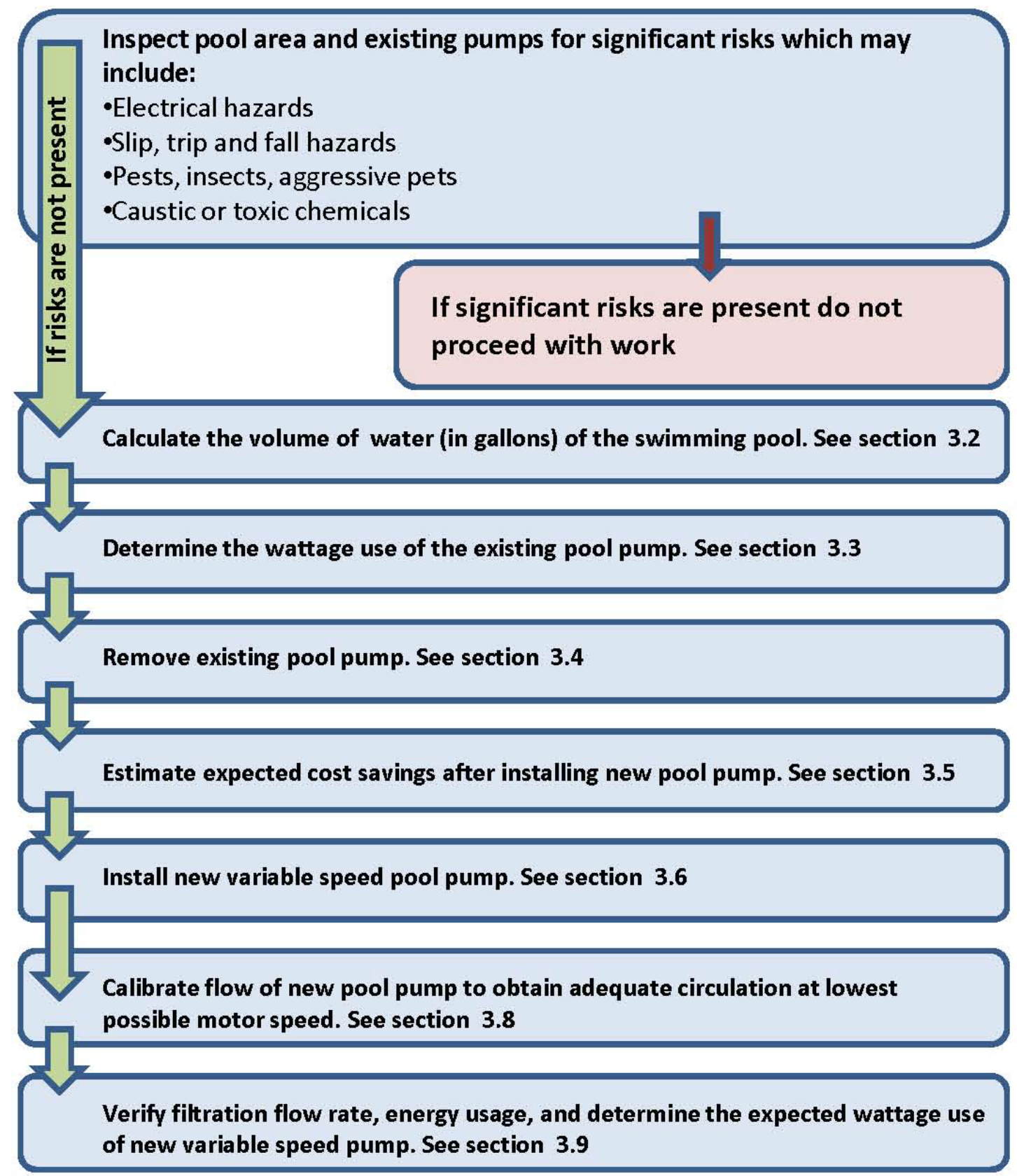




\section{Introduction}

According to a 2008 report by the Natural Resources Defense Council (NRDC) ${ }^{1}$, there are more than 4.5 million in-ground residential pools in the United States, and they consume between $\$ 1.1$ and $\$ 1.6$ billion in energy costs per year. Energy use will differ because of variations in swimming season length, energy rates, whether or not (and how) pools are heated, and other environmental factors. However, the NRDC has estimated that, nationwide, residential inground swimming pools consume between 9 and 14 billion kilowatt hours $(\mathrm{k}-\mathrm{Wh})$ and between 36 and 63 million therms of natural gas each year for pool heating. This results in national $\mathrm{CO}_{2}$ emissions of roughly 10 million tons per year - the equivalent of 1.3 million cars and light trucks on the road. In homes with pools, a pool pump can be the second largest energy user and most often is the largest energy user in the home.

Pool pumps provide an important function for in-ground pools by circulating water through the pool's filtration system. The filtration system keeps the water clean, clear, and sanitary for bathers by screening debris that falls into the pool and also removing algae and microorganisms that can pose potential health threats to swimmers. In addition, pumps may also circulate water through heaters, cleaners (also known as sweeps), water features, or fountains. These single-speed pumps traditionally have a 1- or 2-horsepower motor that will run at least five to six hours per day, if not around the clock, consuming energy.

For a relatively small investment, a variable speed pool pump can reduce pool pump energy use by $50 \%$ to $75 \%$. The majority of the savings is derived from a variable

Understanding the importance of a properly functioning pool circulation system

Although the Association of Pool and Spa Professionals (APSP) suggests that the pump be "capable" of turning over the entire volume of water in the pool two times in 24 hours, the actual turnover rate can be slower when conditions permit. Pools that inadequately filtered can incubate dangerous pathogens (disease-causing microorganisms) and pose a health risk for bathers. Algae, bacteria, viruses, and fungi can thrive in a poorly filtered swimming pool, often introduced into pool water by rain, windborne debris, bathing suits, or poor quality water used when filling. Chemical disinfectants and chlorination can help to reduce the threat of disease and illness, but, a properly maintained and functioning pool pump and filtration system is critical to keeping the swimming water safe and clean. speed pump's ability to reduce the rpm of the motor, thus reducing energy use. A typical $1 \frac{1}{2-}$ horsepower pool pump draws about 2,000 watts and runs at 3,450 rpm. Reducing the pump speed and flow has a tremendous impact on wattage draw due to the Pump Affinity Law. For example, if you reduce the pump speed from $3,450 \mathrm{rpm}$ to $2,400 \mathrm{rpm}$ (30\% reduction in speed) the wattage drops from 2,000 watts to 593 watts ( $70 \%$ reduction in power).

Replacing a single-speed pump with a modern variable speed pump is relatively quick and simple. In order to successfully complete the task, the installer must calculate the number of gallons of water in the pool and calibrate the new pump to circulate water at an appropriate rate.

\footnotetext{
1 J. Rivera, C. Calwell, L. Moorefield, Synergies in Swimming Pool Efficiency: How Much Can Be Saved?, Natural Resources Defense Council, 2008
} 
When completed, the variable speed pump will provide the same service as the traditional pump but at a substantial energy savings for the homeowner.

\section{Cost and Performance}

Replacing a single-speed pool pump with a variable speed pool pump can create equal or greater potential energy savings than realized by updating an existing home to an ENERGYSTAR ${ }^{\circledR}$ rated home. ${ }^{2}$ This section will explore the cost and performance benefits associated with replacing a single-speed pool pump with a variable speed pump as well as discuss the physics behind the Pump Affinity Law and other benefits of pool pump replacement not related to energy.

\subsection{Typical Energy Usage of Single-Speed Pool Pumps}

The primary reason that most singlespeed pool pumps consume an excessive amount of electricity is that

Table 1. Pool Pump Replacement vs. Upgrading to an ENERGY STAR Home they are typically oversized and overused in the course of pool operation. A pool pump is called upon to perform multiple water circulation duties during the operation of the pool. While the primary function of the pool pump is to simply circulate water through the filtration system, other tasks can include powering spa jets, backwashing the filter, operating a chlorinator, providing water for the pool sweeper, circulating water through the heater, initiating flow to a solar panel and pumping water to waterfalls and other water features. These occasional tasks require more energy (a greater flow rate) than the circulation of pool water through the filtration system and account for roughly $10 \%$ of the pool pump's operation time. Often, pools have multiple pumps to provide some of the functions listed above.

Single-speed pumps by design can't change their flow rate so they must be sized to perform the most demanding task. This means that during $90 \%$ of the operational time, single-speed pool pumps provide greater circulation than the pool filtration system requires.

Two-speed pool pumps.

Although not common, installers may encounter a two-speed pool pump during the inspection and replacement process. Two-speed pumps have been available for years and are marketed as an alternative to more expensive variable speed pumps. The two-speed pump uses an induction motor and is basically two motors in one with a standard 3,450 rpm (full-speed) motor and a $1,725 \mathrm{rpm}$ (half-speed) option. Ideally these motors may enable significant energy savings for the homeowner, however, if the half-speed motor is unable to complete the required water circulation task, the larger motor will operate exclusively. Because there is are only two speed choices it is much more difficult to fine-tune the flow rates required for maximum energy savings.

\footnotetext{
${ }^{2}$ Replacing a single-speed pump with a variable speed model and covering a heated pool, can generate savings comparable to those possible by upgrading a 2,500-square-foot, single story home to Energy Star levels.
} 
A standard pool pump is typically $1 \frac{1}{2}$ to $2 \mathrm{hp}$ and operates using a single-speed induction motor generating excessive filtration flow rates. This volume of water is achieved by a 3,450 rpm rate that requires between 1,500 and 2,500 watts of electricity depending on the service factor of the motor.

\subsection{Energy Savings of Variable Speed Pool Pumps}

A variable speed pool pump will allow the homeowner to achieve the ideal filtration flow rate with the least amount of energy consumption. Variable speed pumps utilize either Permanent Magnet Motors (PMM), which use permanent magnets to create a magnetic field between the rotor and the windings. This configuration is similar to the motors used in hybrid cars. Efficiencies are gained by the magnets working to spin the rotor, as opposed to a standard induction motor that requires additional electricity to induce the magnetic field into the rotor. The PMM motor design is much more energy efficient when compared to the standard induction motor, achieving efficiency ratings of $90 \%$ while the average single-speed pump will have efficiency ratings between $30 \%$ and $70 \%$. PMM pumps can produce the same gpm flow rate as single-speed induction motors if needed; they simply run much more efficiently.

The largest energy savings of installing a PMM pump comes from the ability to program and reduce the flow rate to match the required pumping task. Unlike a singlespeed pump that will operate at maximum flow rate even for tasks that require minimum flow rates, the variable speed pump can be slowed down to the optimum level balancing flow rate needs with energy use. In order to fully appreciate how significant these energy savings can be, it is important to understand the physics behind the Pump Affinity Law.

\subsection{Pump Affinity Law Applied}

The Pump Affinity Law is a term used to express the relationship between motor speed, flow rates, and energy consumption. While some energy savings come directly from improved motor efficiency, the majority of energy savings gained by replacing a single-speed pump with a variable speed pump is due to the Pump Affinity Law. This law quantifies that power consumption drops at a nonlinear rate as you reduce pump speed and water flow. When you cut the motor speed in half, the flow rate is also reduced to half, but the power consumption of the pool pump is reduced to $1 / 8$ th of the original draw. The following chart demonstrates how the pump speed and flow rates directly impact power usage. Remember, most single-speed pumps have a standard 3,450 rpm speed that cannot be adjusted, even when a flow rate is much less than $66 \mathrm{gpm}$ is required, as depicted in the example in Table 1. 
Table 2. The Pump Affinity Law - Applied

\begin{tabular}{|c|c|c|}
\hline $\begin{array}{c}\text { Speed } \\
(\mathrm{rpm})\end{array}$ & $\begin{array}{c}\text { Flow } \\
(\mathrm{gpm})\end{array}$ & $\begin{array}{c}\text { Power } \\
(\mathrm{W})\end{array}$ \\
\hline 3,450 & 66 & 2,000 \\
\hline 3,000 & $\mathbf{5 5}^{*}$ & 1,157 \\
\hline 2,400 & 44 & 593 \\
\hline 1,800 & 33 & 250 \\
\hline 1,200 & 22 & 74 \\
\hline 600 & 11 & 9 \\
\hline $\begin{array}{l}* \text { A reduction in 450 rpm almost } \\
\text { unnoticed in the application, cuts the } \\
\text { power almost in half. }\end{array}$ \\
\hline
\end{tabular}

\subsection{Energy and Cost Savings Comparison}

The following example illustrates how replacing a single-speed pump with a variable speed pump can create significant energy savings.

The average residential swimming pool contains 25,000 gallons of water and has a suggested turnover rate of 24 hours. A single-speed pump drawing 2,000 watts, operating at 3,450 rpms and generating a flow rate of 66 gallons per minute can turn over the entire 25,000 gallons of water in roughly 6.3 hours.

\section{$(25,000$ gallons $/ 66$ gpm $) / 60$ minutes $=6.3$ hours}

At this rate the single-speed pump would consume 12,600 watt hours or $12.6 \mathrm{kWh}$ per day, to turn over the pool.

\section{3 hours $x$ 2,000 watts $=12,600$ watt hours $(12.6 \mathrm{kWh})$}

However, because of the Pump Affinity Law, slower flow rates create greater energy savings. In the field, a variable speed pump set at a flow rate of 22 gpm will draw 116 watts and turn the pool over in 19 hours but only consume $2.2 \mathrm{kWh}$ of electricity.

$(25,000$ gallons $/ 22$ gpm $) / 60$ minutes $=19$ hours

19 hours x 116 watts $=2,200$ watt hours $(2.2 \mathrm{kWh})$ 
This is a savings of $10.4 \mathrm{kWh}$ per day, or approximately $3,796 \mathrm{kWh}$ per year. The average retail price of electricity to residential customers in California, where there are an estimated 1.1 million in ground pools, is 14.8 cents per kilowatt-hour. Following this example, the homeowner could realize a savings of $\$ 561$ annually on their electric bill.

Saving energy is a wonderful goal but should not happen at the expense of swimming pool sanitation and water clarity.

\subsection{Performance Comparisons}

Most water clarity problems are caused by improper chemical maintenance, not by debris and silt hovering around indefinitely. Particles large enough to be captured by a filter will sink when the pump is off. This is not to say that the filtration and circulation systems do not impact water clarity; when not run long or fast enough to allow effective chemical feeder/generator operation, they do.. However, it is a common misconception that a slower turnover rate will allow for more contaminants to remain in the pool longer and result in less than ideal water clarity.

When comparing performance issues between singlespeed and variable speed pumps, there are no negative performance issues associated with the variable speed pump. When properly calibrated, the variable speed pump can increase flow rates to be equal to or greater than the existing single-speed pump. However, the performance advantages of a variable speed pump go beyond energy savings. Variable speed pumps are noticeably quieter, require less maintenance, last longer, and, through slower water filtration rates, allow for better and more effective filtration of the pool water. The slower circulation rates also put less strain on the filters, plumbing, and other parts of the system, which reduces the chance of leaks, repairs, or premature plumbing component replacement.

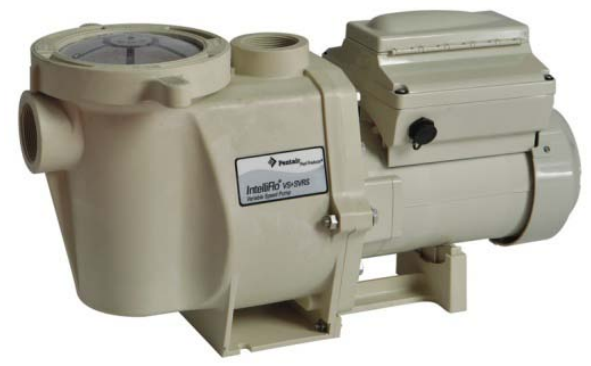

Figure 1. A variable speed pool pump can obtain similar gpm rates as a single-speed pump but at greater energy efficiencies.

Photo from Jeff Farlow, Pentair Water and Spa, printed with permission

Pricing of variable speed pumps remains higher and can be a barrier to adoption during a home retrofit. Although prices may vary, the average cost, with installation, to replace a single-speed pump will range from $\$ 400$ to $\$ 700$. A two-speed pump installation will generally range between $\$ 700$ and $\$ 1,000$, while installation of a variable speed pump, complete with onboard controller and programmable task manager, can cost between $\$ 1,400$ and $\$ 1,800$. In order to offset the additional costs, many utility companies are now providing incentives for installing variable speed pumps. Examples of incentives range from $\$ 75$ in Nevada to $\$ 600$ in Florida. The Database of State Incentives for Renewables \& Efficiency (DSIRE) has more information on the availability of rebate programs for installing variable speed pool pumps at http://www.dsireusa.org/. 


\section{Installation of Variable Speed Pool Pumps}

The pool pump replacement process requires a complete inspection of the outdoor swimming pool area followed by an evaluation of the energy usage and filtration flow rate of the existing pump. It also requires the removal of the existing pump and, finally, the installation and calibration of the variable speed pump. This section will include safety and health practices as well as pool volume calculation methods that are required during the inspection and replacement of the pool pump.

\subsection{Inspecting the Pool Area}

The health and safety of the pool pump installer, as well as the occupants, should be a critical part of the pool pump replacement process. Prior to beginning pump installation, the installer should carefully inspect the entire pool area for exposed wiring, trip hazards, pests, or animals. A thorough inspection of the pool pump containment area and any exposed plumbing should also be done to ensure that any leaks or damage to existing pool plumbing are identified and repaired. Finally, the installer should locate the main electrical circuit breaker panel and identify and confirm which breaker is designated for the pool pump.

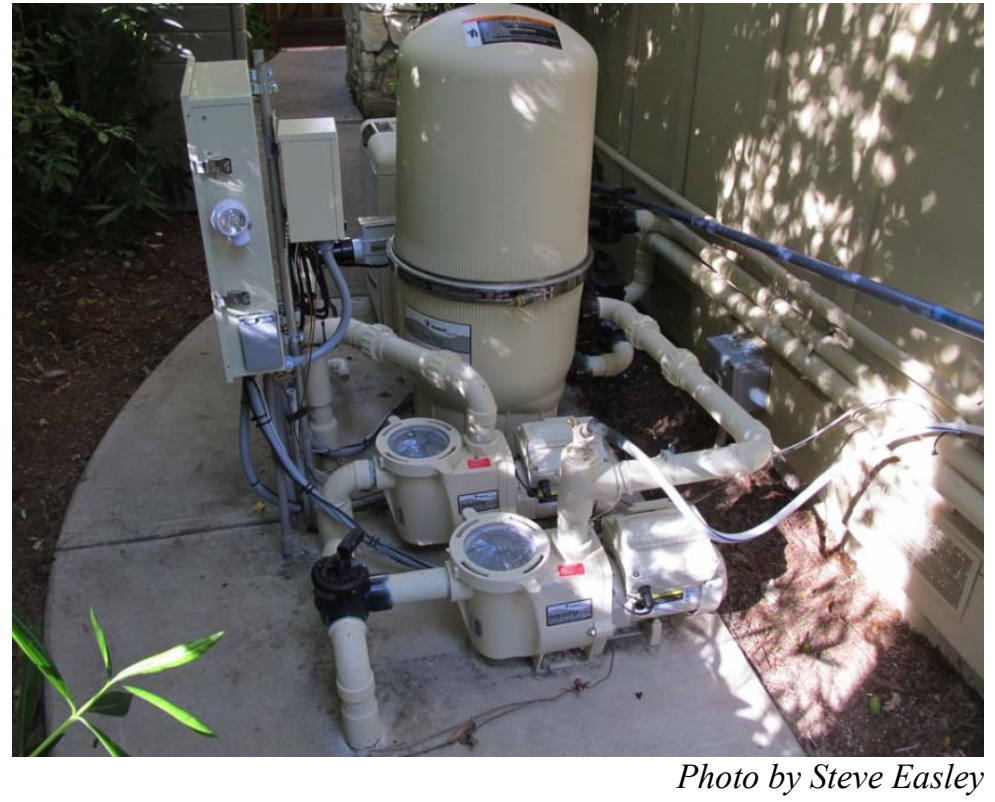

Figure 2. Inspecting the equipment pad for potential health and safety risks is critical before beginning work.

\subsection{Measuring the Pool and Calculating Pool Volume}

There are two important reasons why an installer must accurately calculate the volume, in gallons, of water in the pool. First, the pool pump must have the correct flow rate (volume of water that passes through the pump) in order to meet the proper turnover rate and maintain clarity and sanitary conditions in the pool. If the pump is unable to turn over the entire volume of water within a 24-hour period, the risk of algae and pathogens can increase. A turnover every 24 hours is the minimum flow rate for the pool pump. To calculate the minimum flow rate of the pool pump, divide the total volume of the pool in gallons by 1,440 (total minutes in a day).

\section{Total volume of pool / $1440=$ Minimum Filtration Flow Rate (gpm)}

The minimum filtration flow rate is the least amount of water (gpm) the pool pump must circulate through the filtration system in order to achieve the minimum daily turnover.

The second reason for calculating the pool volume is to determine the maximum pool filtration rate. The pool pump should not have a filtration rate greater than the rate needed to turn over the 
pool water volume in six hours, or 36 gallons per minute $(\mathrm{gpm})$, whichever is greater. This equation was developed by the California Energy Commission and was adopted by the Association of Pool and Spa Professionals to help set guidelines for achieving the maximum energy efficiency in pool pump operation. To calculate the maximum filtration flow rate, divide the total volume of water in the pool by 360 .

\section{Total volume of pool /360 = Maximum Filtration Flow Rate (gpm)}

For pools with less than 13,000 gallons, the pump must have a gpm rating of 36 gpm, or less.

In order to determine the maximum and minimum pool filtration rates, the installer must first calculate the entire volume of pool water in cubic feet, and then multiply by 7.48 (number of gallons of water contained in one cubic foot of water) to determine the total number of gallons. For simple, flat-bottomed, rectangular swimming pools this is a relatively easy calculation to perform by simply measuring and multiplying the length, width and depth of the pool.

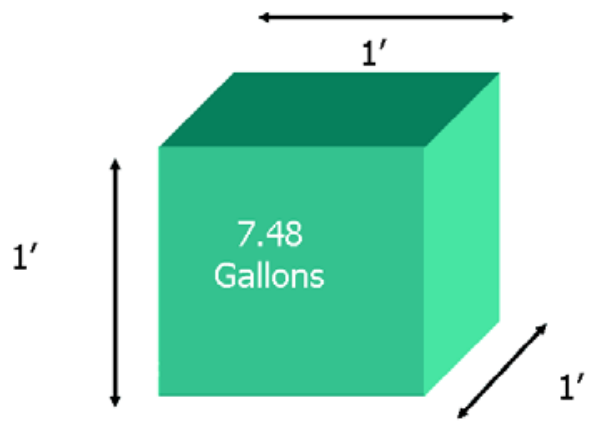

Figure 3. How to determine total volume in gallons

\section{length $x$ width $x$ depth of water = cubic feet of pool (volume of water)}

\section{Volume of water in cubic feet $x 7.48=$ Total volume in gallons}

For instance, a rectangular pool that is 24 feet long by 16 feet wide with a consistent depth of 5 feet would have a total volume of 1,920 cubic feet of water when completely filled.

$$
24 \times 16 \times 5=1,920 \text { cubic feet }
$$

Once the total cubic feet of water has been calculated, that amount can be multiplied by 7.48 (gallons per cubic foot of water) to determine the total number of gallons in the pool.

\section{$1,920 \times 7.48=14,362$ gallons of water}

However, because pools come in countless designs, shapes and depths, calculating pool volume is rarely so simple. In order to calculate oblong, circular, sloped, nonlinear sloped and custom pool designs, more advanced mathematical calculations are required. There are several free pool volume calculation tools available online, including on the Pentair Pool and Spa website at (http://www.pentairpool.com/pool-owner/resources/calculators/pool-volume-calc/poolcalc.htm).

Once the total pool volume in gallons has been determined, the installer can calculate the maximum and minimum filtration rates. This information will help calibrate the new pool pump to make sure it is operating at peak performance from both a healthful and energy efficient standpoint. 


\subsection{Evaluating Energy Usage of Existing Pool Pump}

The conventional way to calculate the amount of watts an appliance or electrical device uses is to multiply amps times volts. While this method works for an electrical direct current (DC) circuit, it is not an accurate way to calculate energy use of alternating current (AC) motors.

The equation for motors is:

\section{Amps $x$ Volts $x$ Power Factor $=$ Watts}

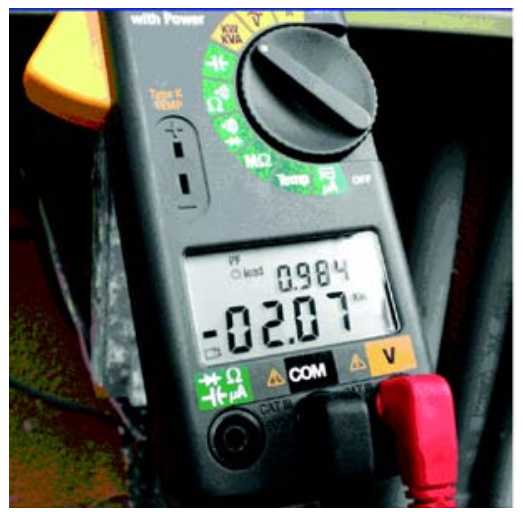

Figure 4. The RMS kilowatt meter can quickly and easily determine the pool pump's electrical consumption rate.

Photo from Jeff Farlow, Pentair Water and Spa, printed with permission

Although every motor has a power factor rating, it can be difficult to access this information for every pump on the market, as the service factors and load factors all vary.

The best way to determine $\mathrm{kW}$ usage is with an RMS kilowatt meter, which tells you instantly how many kW's the pump is using. Using a $\mathrm{kW}$ meter is just like using an Amp meter but you must measure both volts and amps. First, put the meter dial on $\mathrm{kW}$ and turn the pump on. Next. place the black and red leads on the terminals supplying voltage to the pump (this can be done at the time clock or relay, depending on the installation). Then, clamp the meter around one of the hot wires and read the pump's $\mathrm{kW}$ usage. As with any electrical wiring evaluation, extreme care should be taken when using the RMS kilowatt meter, especially around areas that have standing water.

Once the wattage use of the pump has been determined, it is possible to calculate the kilowatt hours, daily and annual energy consumption of the motor, and the estimated cost of the pool pump operation.

For example, after using the RMS kilowatt meter on a $11 / 2$-hp single-speed pump; a reading of $2.07 \mathrm{~kW}$ is measured. In order to determine the energy consumption and estimated cost, first convert that reading to kilowatthours.

\subsection{7 kilowatts $X 1$ hour $=2.07 \mathrm{kWh}$.}

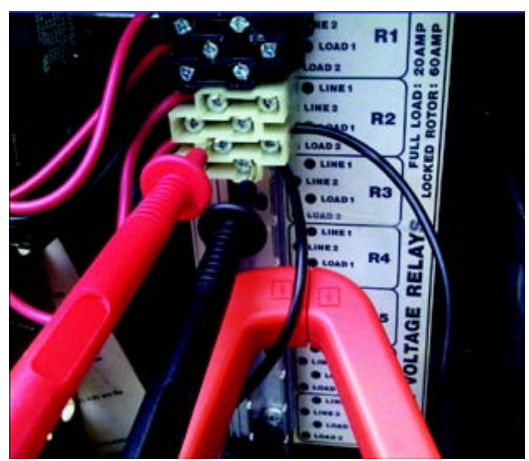

Figure 5. Extreme caution should be used when using the RMS kilowatt meter to determine pool pump electrical usage.

Photo from Jeff Farlow, Pentair Water and Spa, printed with permission

As such, in one hour, the pump will consume $2.07 \mathrm{kWh}$. Next, determine the average number of hours the pump is used daily. This can be done by reviewing the timer and by interviewing the homeowner. If the pump normally runs for six hours a day, then multiply 2.07 by 6 . 
A common question related to pool pump power usage relates to how a $1 \frac{1}{2}$-hp motor can draw 2.07 kilowatts. This is because motors also have a service factor (SF) rating or overload capacity designed into the motor. There is a practice in the swimming pool pump industry of using high service factors where the total horsepower (and subsequent $\mathrm{kW}$ demand) is much greater than the nameplate would imply. For general-purpose motors, service factors would rarely be higher than 1.15. However, swimming pool motors are definite purpose motors designed exclusively for use in the pool industry. These motors are designed with exceptionally large service factors as high as 1.65 or 1.9 . The result is that a $1 \frac{1}{2}$-hp pump with a service factor (SF) of 1.47 can easily draw around 2,100 watts or $2.1 \mathrm{~kW}$.

\section{Rated HP x SF x 746 Watts per HP/Motor Efficiency = Watts}

\subsection{HP $x 1.47 \times 746$ Watts per HP / 78\% = 2108 Watts}

\subsection{Estimate Energy Usage and Savings of a New Pool Pump}

Once the energy usage of the existing pool pump has been determined, it is easy to calculate the expected energy savings associated with installing the new variable speed pool pump. To do this, first use the pool volume calculation to determine the acceptable filtration rate. Once the flow rate has been determined, you can calculate expected energy usage by referencing the product manual of the new pool pump.

In general, the slower turnover rates associated with variable speed pool pumps should reduce energy usage between $30 \%$ and $70 \%$ annually, however there are many variables to consider. Because there is such a wide range of pool circulation systems, conditions, and filtration needs, specific savings and performance data can only be accurately determined after the variable speed pool pump has been installed. Pool volume, ambient temperature, use, age of system, water quality, covering, local environment (trees, grass, dirt, sand) and accessories (waterfalls, cleaners, scrubbers, fountains) all impact potential cost savings. Calculating the exact energy savings before installation may not be possible; however, comparing the existing pump usage with potential savings based on the model and type of pool pump to be installed can help encourage homeowners to invest in pool pump replacement.

\subsection{Remove an Existing Pool Pump}

Being prepared for the removal of the existing pool pump and installation of the new variable speed pump can make the task simpler and faster. The actual process of removing and replacing the pump is not a difficult task; however, care should be taken to ensure the safety of the worker and occupants of the home and their property. Removal and replacement of the pool pump requires the tools needed for rewiring any basic electric circuit and cutting and gluing PVC pipe. These include:

- Electrical meter: preferably True RMS clamp-on $\mathrm{kW}$ and multi-function style meter.

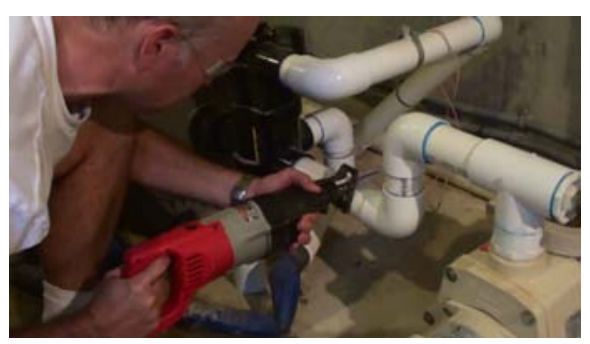

Figure 6. A reciprocating saw often works well to cut PVC pipe during the installation process.

Photo from Jeff Farlow, Pentair Water and Spa, printed with permission 
- Miscellaneous: Screwdrivers, slip-joint pliers, channel-lock pliers, wire cutters, wire strippers, wrenches, sand paper.

- Pipe cutter: ratcheting PVC cutter, reciprocating saw, chop saw or hacksaw.

Before removing the pump, verify the electrical supply voltage and wire and circuit breaker size and ensure that these are compatible with the replacement variable speed pump and in accordance with national, state, and local codes and permits.

When selecting common PVC fittings, use of schedule 40 or 80 pipe is recommended. It is not advisable to use lower pressure rated drain, waste, vent (DWV)-style pipe and fittings for pool circulation systems. Though rare, occasionally copper pipe may be found in older pools.

To expedite the installation process, installers should have ample inventory of common materials such as $90^{\circ}$ elbows, $45^{\circ}$ elbows, couplings, unions, valves, pipe, PVC glue and primer, threaded nipples to attached to the pump, pipe thread compound or Teflon tape. Prior to installation, it is important to inspect and note the threaded fitting size of the replacement pump housing. Most are 2" male pipe thread (MPT), and some pumps come equipped with the threaded fittings and unions.

When inspecting the area, also measure the overall pump dimensions and compare the existing pump to the replacement variable speed unit. Pay special attention to the suction port height, and distance from pump suction port to discharge port as these critical dimensions vary amongst pumps. Have a plan for how the replacement pump will fit and where it is best to make cuts before the old pump is removed from service. Also note locations of junction boxes to ensure sufficient wire and conduit is available.

Once preparation is complete and current electrical consumption has been measured and recorded, removal of the existing pump can begin.

The process for removing the pump is as follows:

1. Open the circuit breaker to disconnect electricity to the pump.

2. Verify that the pump has been de-energized by checking with an electrical meter.

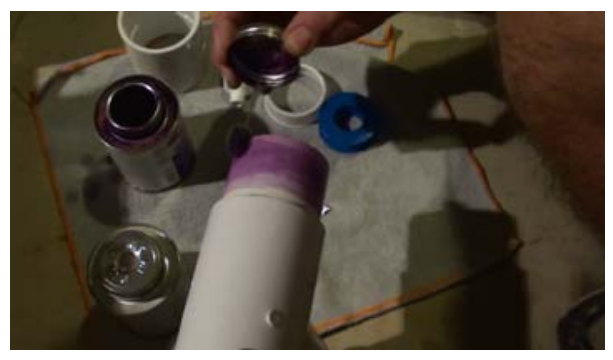

Figure 7. Thread sealant or pipe glue will help ensure fittings remain connected and leak-free.

Photo from Jeff Farlow, Pentair Water and Spa, printed with permission

3. Disconnect electrical wires at the pump junction box.

4. Mark the location and use pipe cutter or hacksaw to cut the discharge and suction pipe.

5. Remove the existing pump. 


\subsection{Installing a Variable Speed Pump}

Once the existing pump is removed, ensure that the work area is clean and free of obstructions. Place the replacement pump in position and align the suction and discharge pipes. Shims may be required to compensate for varying pump heights and should be used to create a level and stable connection height. Install threaded fittings in pump suctions and discharge ports using thread sealant.

Avoid installation of $90^{\circ}$ elbows directly into the pump inlet as these greatly increase friction or total dynamic head (TDH). If the installation allows, install a length of straight pipe at the pump's suction port that is equal to five times its diameter. For example, with a 2 " diameter pipe, it is recommended to install a straight pipe 10" long prior to entering the pump's inlet. This practice will aid in the pump's priming and general performance.

\subsection{Connecting Fittings and Making Electrical Connections}

After all fitting and connections have been made, reconnect the electrical conduit and wires per national, state, and local codes. Also, ensure the ground bonding wire is connected to the pump's bonding lug.

Most existing single-speed pumps are electrically powered through a timer or automation system to schedule their daily operation. Newer variable speed pumps have the time clock and scheduling feature inherent in their control system. For these pumps, it is preferable to wire them directly, bypassing the existing time clock. For installations with remotely operated automaton systems, the pump may be powered through relays. This is done to ensure that the pump has a continuous uninterrupted power supply.

\subsection{Calibrating Variable Speed Pump for Optimum Performance}

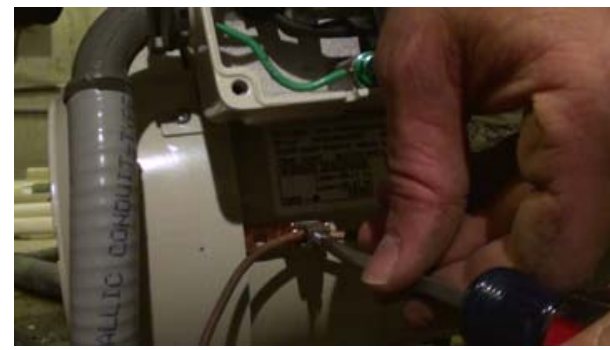

Figure 8. Make sure the ground bonding wire is securely fastened to the pump's bonding lug.

Photo from Jeff Farlow, Pentair Water and Spa, printed with permission

After installation is complete, the installer must program the new pump to obtain adequate filtration, in-pool circulation, and water clarity while using the lowest possible motor speed.

Filters only capture what is suspended in the water passing through them, and only what is large enough to collect on the filter media. Once debris and sediment enters the water, one of three things will happen: it will float, sink, or get suspended in the water. Floating matter can be skimmed off the surface to be collected and removed, but once it sinks to the floor, it will stay there without some kind of help to remove it. Variable speed pumps need to run longer to accomplish the required turnover due to their lower flow rates. As a result, the pool spends much more time skimming the water and preventing debris from sinking. The result is a cleaner pool with improved water clarity and is another benefit

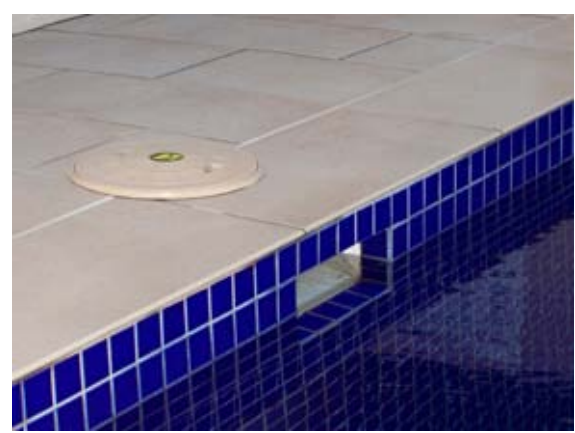

Figure 9. The skimmer is the port that draws water from the pool and into the filtration system.

Photo from Jeff Farlow, Pentair Water and Spa, printed with permission 
derived from running pumps at a slower rate and for longer periods of time.

The variable speed pump should be set up to operate at a speed that will turn over the pool volume at least once during every 24-hour period. For pools with high debris and/or bather loads, additional turnovers may be required to maintain adequate water quality. In no event should the turnover time be less than six-hours during normal operation.

Reducing the flow through main drains by throttling the drain's return line valve (if applicable) can improve skimmer performance by providing the pump with most, or all of the water from the skimmer. However, this configuration must be tested to confirm the pump is supplied with enough water when operating the pump at

\section{Caution!}

During the removal and installation process, air can enter the system and become pressurized. Excessive pressure can result in an explosion of the filter housing. Before system start-up, the pump and system must be manually primed and evacuated of air. Care should be taken to vent system air through the filter's manual relief valve. the highest speed needed by the pool. This is often not the highest speed at which a pump can operate and should only be high enough to achieve the intended purpose, such as operating cleaner therapy jets, or a water feature.. Essentially, the goal is always to provide sanitation and to accomplish the desired feature operation at the lowest flow rate.

The start-up flow rate may need to be higher for several minutes to fully prime the pump, purge air from the filter, and fill solar panels with water. Once these start-up tasks have been completed, the pump speed can be reduced to the energy efficient low-speed setting.

Pools sometimes need higher turnover flow rates. For example, following a storm or pool party, higher turnover flow rates may be required It is advantageous to have this feature set up in advance to provide the pool owner with a mode that will temporarily override the normal filtration flow rate without the need for reprogramming the pump controller.

\subsection{Verification and Filtration Flow Rate Testing}

Always follow the pump manufacturer's instructions and guidelines, especially the warning and safety instructions. The instructions listed here are not intended to be comprehensive and do not substitute for adherence with the manufacturer's instructions.

During the removal and installation process, air can enter the system and become pressurized. Before system start-up, the pump and system must be manually primed and evacuated of air. Care should be taken to vent system air through the filter's manual relief valve.

Caution: do not run the pump dry. To prime, remove the strainer pot lid and fill the pump with water until the level reaches the suction port, and then replace the strainer pot lid. This prevents the pump from running dry, which will damage the mechanical seal. Start by opening the manual relief valve on top of the filter and then press the button to start the pump. Next, you must bleed air from the filter until a steady stream of water comes out, and then close the manual air relief valve. 
Remember, the basic premise of variable speed energy-saving pump operation is "run it slower and run it longer." By running the pump slower, a slight reduction in water flow (gpm) will greatly reduce the electrical demand $(\mathrm{kW})$. By reducing the flow rate, runtime will have to increase to ensure that the water is adequately filtered and mixed.

After the pump has been started and is successfully circulating water through the filtration system, filtration flow rates need to be verified. Water is supplied to the pump from both the skimmers and main drains; however, the skimmers should supply the majority of the flow. Minimum filtration flow rates need to ensure that the skimmers function adequately. Most skimmers take approximately 25 gallons per minute (GPM) of flow for adequate performance. Verification of performance can usually be accomplished by visually observing surface water drawn into the skimmer face and over the weir door. Skimmer baskets need to be checked and cleaned regularly. Main drain flow should complement the skimmer flow but should be minimized to prevent suction entrapment hazards. The main drain and suction covers should be visually observed. A broken or missing drain cover poses a serious health risk and should be replaced immediately, even before the pool is returned to service.

\subsection{Programmable Pumps and Maintenance}

Note that some variable speed pumps may be capable of producing a maximum flow rate higher than the existing single-speed pump. Excessive flow rates can present hazards such as suction entrapment. Use caution when installing and programming to limit pump's performance potential with old or questionable equipment and to avoid suction entrapment hazards.

Many variable speed pumps have the ability to schedule features throughout the day. As such, the pump may unknowingly start to initiate a scheduled feature. Never leave the pump unattended and power supplied while the pump is in an unsafe condition unless the pump's programming cycles are understood (for example, strainer pot lid removed or pipes not connected and system not primed).

Maintenance for variable speed pumps is generally the same as that for single-speed pumps.

Pump strainer baskets (sometimes referred to as "hair and lint pot") must be kept clean of leaves and debris at all times. A dirty basket can impact pump and system performance and make the system difficult to prime.

Protect motors from heat by ensuring that there is shade from the sun and that ample ventilation is available. Particular attention should be paid to the motor's fan cover and cooling fins to ensure there are no obstructions to air flow.

Motors should also be protected from dirt and moisture. Avoid splashing with water. Do not store or spill chemicals next to the motor. Avoid installations next to lawn sprinklers and protect them from the weather.

Some variable speed pumps come equipped with freeze protection to assist with winterization. This feature will automatically start the pump when temperatures reach a predetermined level to prevent freezing of the pipes. Whenever systems are drained, power should be removed from the pump to avoid inadvertent starting of the pump. 
Once the variable speed pool pump has been successfully installed and tested, the next critical step is to train the homeowner on the capabilities, functions, operation, maintenance, programming, and potential risks associated with the new pump. In order to ensure that energy savings are actualized, the homeowner must understand that the lower flow rates will provide adequate filtration for the pool However, it is also important to educate the homeowner on the signs of a potentially unclean pool and equip them with information and knowledge to maintain a healthy swimming environment.

The final step in installing the new pump is to accurately measure the energy use of the new pump and compare it the findings when you measured the energy use of the old pump. This comparison will act as a guide for the homeowner to understand optimum pump use and potential savings. 


\section{Attachment A: Prescriptive Measure Checklist}

The nature and scope of installing a variable speed pool pump can vary substantially. Based on these guidelines, the checklist below is presented as a potential framework (though not an exhaustive resource) for conducting existing pump removal and new pool pump installation.

1. Inspect the pool and pool pump area for significant risks. Are any of the following present?

If the answer is YES to any of these or if other serious risks are identified, do not proceed with work until the risks have been addressed.

Exposed wiring or electrical concerns

Pests, aggressive pets, or dangerous animals present

Significant structural damage to pool or filtration system plumbing

Caustic or toxic chemicals present

YES

YES

YES
YES
NO

NO

NO

NO

\section{Calculate the volume of water (in gallons) of the swimming pool.}

For details, see section 3.2 of main document.

Basic equation for calculating pool volume in gallons:

Length $\times$ Width $\times$ Average Depth $\times 7.48=$ total gallons

\begin{tabular}{|l|l|}
\hline Length & \\
\hline Width & \\
\hline Average depth & \\
\hline Total volume of water in gallons & \\
& \\
\hline
\end{tabular}


3. Determine the wattage and energy consumption use of the existing pool pump.

For details, see section 3.2 of main document.

Basic equations for calculating kWh, daily and annual usages are:

\begin{tabular}{|l|l|}
\hline \multicolumn{1}{|c|}{ Task } & Result \\
\hline $\begin{array}{l}\text { Existing pool pump power in } \mathrm{kW} \text { (as } \\
\text { determined by using RMS kilowatt meter) }\end{array}$ & \\
\hline $\begin{array}{l}\text { Daily } \mathrm{kWh} \text { usage } \\
\mathrm{kW} \text { x hours of use per day }=\mathrm{kWh} / \text { day }\end{array}$ & \\
\hline $\begin{array}{l}\text { Annual } \mathrm{kWh} \text { usage } \\
\text { Daily } \mathrm{kWh} \text { usage } \mathrm{x} \text { days per year of } \\
\text { operation = annual } \mathrm{kWh} \text { usage }\end{array}$ & \\
\hline
\end{tabular}

\section{Remove existing pool pump.}

For details, see section 3.4 of main document.

The steps for pump removal are as follows:

1. Open the circuit breaker to disconnect electricity to the pump.

2. Verify that the pump has been de-energized by checking with an electrical meter.

3. Disconnect electrical wires at the pump junction box.

4. Mark the location and use pipe cutter or hacksaw to cut the discharge and suction pipe.

5. Remove the existing pump.

\section{Install new variable speed pool pump.}

For details, see sections 3.5 and 3.6 of main document.

The steps for pump installation are as follows:

1. Place replacement pump in position and align suction and discharge pipes.

2. Shim as needed to create level and stable connection.

3. Install threaded fittings using thread sealant.

4. Reconnect the electrical conduit and wires per national, state, and local codes.

5. Ensure the ground bonding wire is connected to the pump's bonding lug.

6. Avoid installing pump in locations without shade from the sun or inadequate ventilation.

WARNING: During the removal and installation process, air can enter the system and become pressurized and lead to explosion. Before system start-up, the pump and system must be manually primed and evacuated of air. 


\section{Calibrate and program flow of pool pump}

For details, see section 3.7 of main document.

The steps for pump programming and calibration are as follows:

1. Determine the lowest flow rate possible for 24 -hour turnover of the pool water volume.

2. Program additional turnover rates for heavy use, but never greater than a six hour rate.

3. Visually inspect that, at the minimum, flow rate water is entering the skimmer.

4. Visually inspect that the drain covers are in working order and are in place.

5. Review pump programming and operation with homeowner.

\section{Calculate energy savings of new pump}

For details, see section 3.8 of main document.

\begin{tabular}{|l|l|}
\hline \multicolumn{1}{|c|}{ Task } & Result \\
\hline Existing pool pump daily usage in $\mathrm{kWh}$ & \\
\hline New pool pump daily usage in $\mathrm{kWh}$ & \\
\hline Existing pool pump annual usage in $\mathrm{kWh}$ & \\
\hline New pool pump annual usage in $\mathrm{kWh}$ & \\
\hline Annual Saving $\mathrm{kWh} /$ year & \\
\end{tabular}




\section{Attachment B: Pool Pump Installation Case Study}

In October 2010, the upgrades described here were completed in an attempt to reduce the pool's energy consumption and its owner's electricity bill.

California has a tiered electric utility rate structure, so the more kilowatt-hours used, the more customers pay per $\mathrm{kWh}$. It ranges from $\$ 0.12$ to $\$ 0.40$ per $\mathrm{kWh}$, and swimming pools almost always correlate to the higher rate. Before the upgrades, it was costing $\$ 2,100$ per year to run the filtration, cleaner, light, and solar heating of this 20,000-gallon pool. A separate waterfall pump also consumed energy, but was rarely used because it was loud and inefficient.

\section{Before}

11/2-hp standard pool pump (for filtration and solar heating); sweep-style

pool cleaner with a $3 / 4-h p$ booster pump; 2-hp waterfall pump; one 500

watt incandescent light

The original single-speed pump ran an average of six hours per day during the summer months, drawing about 2100 watts for filtration and heating. The pool cleaner's booster pump, which ran for about 2.5 hours per day, drew an additional 1400 watts. Combined, these two pumps were using an average of $16 \mathrm{kWh}$ per day.

\section{After}

Variable-speed pump (for filtration, solar heating and pool cleaner);

Second variable-speed pump for waterfall; LED lighting

The variable-speed pump draws 221 watts during the low-flow filtration cycle, and 650 watts when it speeds up to operate the pool cleaner.

The cleaner's booster pump is no different ( $3.4 \mathrm{kWh}$ per day). Together, that is $16 \mathrm{kWh}$ per day in the summer. The new variable-speed pump requires only $1.3 \mathrm{kWh}$ per day for filtration and an additional $2 \mathrm{kWh}$ for cleaning (as shown above), for a total energy use of $3.3 \mathrm{kWh}$ per day after the retrofit. That is a difference of $12.7 \mathrm{kWh}$ per day $(16.0-3.3=12.7)$ in pumping energy savings.

Table 3. Single-Speed Pool Pump Replacement with Variable Speed Pump Operating Cost comparison

\begin{tabular}{|l|c|c|c|c|}
\hline \multicolumn{4}{|c|}{ FILTER PUMP OPERATING COST COMPARISON } \\
\hline \multirow{2}{*}{ Function } & \multicolumn{3}{|c|}{ Old pumps } & New variable-speed pump \\
\cline { 2 - 5 } & summer & winter & summer & winter \\
\hline \multirow{3}{*}{ filtration } & 2092 watts 6 hours & 2092 watts 4 hours & 221 watts 6 hours & 221 watts 3 hours \\
& per day $12.6 \mathrm{kWh}$ & per day $8.4 \mathrm{kWh}$ & per day $1.3 \mathrm{kWh}$ & $\begin{array}{c}\text { per day } 0.66 \mathrm{kWh} \\
\$ 16 \text { per month }\end{array}$ \\
& $\$ 153$ per month & $\$ 102$ per month & month \\
\hline \multirow{2}{*}{ cleaner } & (year round) 1372 watts 2.5 hours per day & (year round) 650 watts 3 hours per day 2.0 \\
& $3.4 \mathrm{kWh} \$ 42$ per month & \multicolumn{2}{c|}{ kWh $\$ 24$ per month } \\
\hline
\end{tabular}


A single-speed waterfall pump has also been replaced with a second variable-speed pump. The old waterfall pump was so loud it was difficult to talk over, and there was no possibility of changing the waterfall's volume of water or sound, so it was rarely used. Plus, it cost almost \$1 per hour to run. With a variable speed pump running the waterfall, the look and sound of the waterfall are adjustable, and, even at higher speeds, the pump is exceptionally quiet. The result is a quieter, more pleasant experience at a far lower energy cost. Best of all, it uses about 900 watts on its high setting compared with more than 2400 watts used by the old single-speed pump, and less than 200 watts on its lower setting.

Table 4. Waterfall Pump Operating Cost Comparison.

\begin{tabular}{|c|c|}
\hline Old single-speed pump & New variable-speed pump \\
\hline 2418 watts / \$0.97 per hour & $\begin{array}{c}905 \text { watts }- \text { high flow } / \$ 0.36 \text { per hour 351 watts medium flow } \\
/ \$ 0.14 \text { per hour } 187 \text { watts - low flow } / \$ 0.07 \text { per hour }\end{array}$ \\
\hline
\end{tabular}

The pool's lighting was also upgraded from a 500 watt halogen to a 50 watt LED, giving it a brighter, more dramatic appearance, as well as the ability to change colors. The improved filter performance also enhances lighting because the water is clearer. More importantly, LED lights are rated to last 20,000 hours, compared with about 4,000 hours expected of the pool's original halogen lights. As such, they require replacement far less frequently.

The net savings from changing the pumps and lights is about $\$ 125$ per month, plus additional savings in reduced filter costs have a total savings of $\$ 1,670$ per year. In addition, the filter is performing better and more efficiently due to slower flow. As a result, the pool water is cleaner, the water clarity has improved, and the appropriate sanitizer levels are maintained. 


\section{Attachment C: Material Specifications}

When specifying pool pumps, labeled NSF Certified, and UL registered products should be selected. NSF is a mark signifying the evaluation to NSF Standard 50 for Self-Priming Centrifugal Pumps for Swimming Pools, spas, and hot tubs. A UL mark signifies evaluation to U.S. Standards UL1081 for Permanently Connected Swimming Pool and Spa Pumps. 


\section{References}

U.S. Energy Information Administration. “Appliances in U.S. Households, Selected Years, 1980-2001” U.S. Energy Information Administration. http://www.eia.gov/emeu/reps/appli/us table.html. Accessed June 12, 2011.

The Association of Pool \& Spa Professionals. "ANSI/APSP/ICC - 15 American National Standard for Residential Swimming Pool and Spa Energy Efficiency" The Association of Pool \& Spa Professionals, www.apsp.org

Michigan State University, "Pests of Pools." http://www.pested.msu.edu/Resources/bulletins/pdf/2621/E2621chap2.pdf Accessed June 20, 2011.

U.S. Energy Information Administration. "Average Retail Price of Electricity to Ultimate Customers by End-Use Sector, by State, February 2011".

http://www.eia.gov/cneaf/electricity/epm/table5_6 a.html. Accessed June 23, 2011.

Best Practices for Energy Retrofit Program Design - Best Practices White Paper, copyright 2010, Home Performance Resource Center.

Synergies in Swimming Pool Efficiency: How Much Can Be Saved?, J. Rivera, C. Calwell, L. Moorefield, Ecos Consulting for the Natural Resources Defense Council, March 24, 2008.

i

The California Energy Commission's Title 20 Appliance Efficiency Standards require that any pool pump with total horsepower of 1.0 or greater must be capable of operating at two or more speeds. Further, section 165.3 (g)(5) requires all residential single-family pool pumps to be operated by a programmable controller capable of switching speeds automatically and defaulting to the low-speed setting after 24 hours if manual high-speed override is activated. 


\section{U.s. DEPARTMENT OF Energy Efficiency \& ENERCY Renewable Energy}

